\title{
VOLATILITY SMILE AT THE RUSSIAN OPTION MARKET
}

\author{
D. Golembiovsky ${ }^{1}$, I. Baryshnikov ${ }^{2}$ \\ 'Bank ZENIT, Russia, +7 (095)937-07-37,d.golembiovsky@zenit.ru, \\ 2Sistema Telecom, Russia, +7 (095)105-74-46, baryshnikov@sistel.ru
}

Received 23 September 2005; accepted 7 December 2006

\begin{abstract}
The main derivative exchange in Russia is FORTS (Futures and Options in RTS) which is a division of Russian Trade System (RTS). The underlying assets of option contracts are futures on Russian companies' shares: OJSC "EES"1, OJPC "Lukoil" 2 and OJSC "Gazprom"3. A basic model for estimation of fair option price is Black-Scholes model, developed in the beginning of 70-s' years of the last century. This model defines the option premium as a cost of its hedging by underlying asset. It uses a number of assumptions: prices of underlying assets follow log-normal distribution; hedging is accomplished continuously; an underlying asset is infinitely divisible; a volatility is constant on all period of option life. However, according to practice, prices of shares and futures do not follow normal or log-normal distribution, a volatility can change during a life of option, and hedging is a discrete process. Thus, Black-Scholes model can yield inexact results in real markets, especially it concerns deeply "in the money" or deeply "out of the money" options. The basic purpose of the paper is to investigate opportunities to apply Black-Scholes model for an estimation of option premiums in the Russian market.
\end{abstract}

Keywords: derivative exchange, Russian Trade System, Black-Scholes model

\section{Black-Scholes model and volatility smile}

It is very important to estimate an implied volatility for option market analysis. If an implied volatility is used in Black-Scholes model, the current market price of an option will be the result of the calculation. An implied volatility is calculated by solving the the corresponding nonlinear equation.

Options' implied volatilities for the various strike prices can be different in a real market. If an options' implied volatility with smaller and larger strikes is higher than "at the money" option's volatility, a plot of the dependence of an implied volatility from a strike can be named as a "volatility smile". There are some reasons of the smile occurrence. A volatility of an underlying asset changes according to some stochastic process. It is not a constant as it is postulated in Black-Scholes model. In a real market historical and implied volatility of options are differ

\footnotetext{
${ }^{1}$ Russian uniform power system.

${ }^{2}$ Russian Private oil company.

${ }^{3}$ Russian state-owned company.
}

too. Fig1 shows the typical plots of "at the money" options' implied and historical volatility. They can be close to each other, but also can be different for some period of time. There is an obvious statistical connection between these two kinds of volatility: a historical volatility bull trend causes increase of implied volatility of options; a historical volatility bear trend leads to downturn of options' implied volatility. Sometimes an implied volatility change is a harbinger of respective alteration of historical volatility.

A plenty of works is devoted to experimental researches of Black-Scholes model accuracy. In work [1] results of experiments on options discrete hedging for the American shares are considered. This research is based on real historical data. The reasons of the disbalance between cost of hedging and the theoretical price of "at the money' options are analyzed. It is judged that this disbalance can't be explained only by effect of discrete hedging. A variable volatility character and a presence of price jumps bring to hedging mistakes.

In work [2] it is told about similar experiments for "at the money", "out of the money" and "in the money" options. The price process is formed by simulation. 


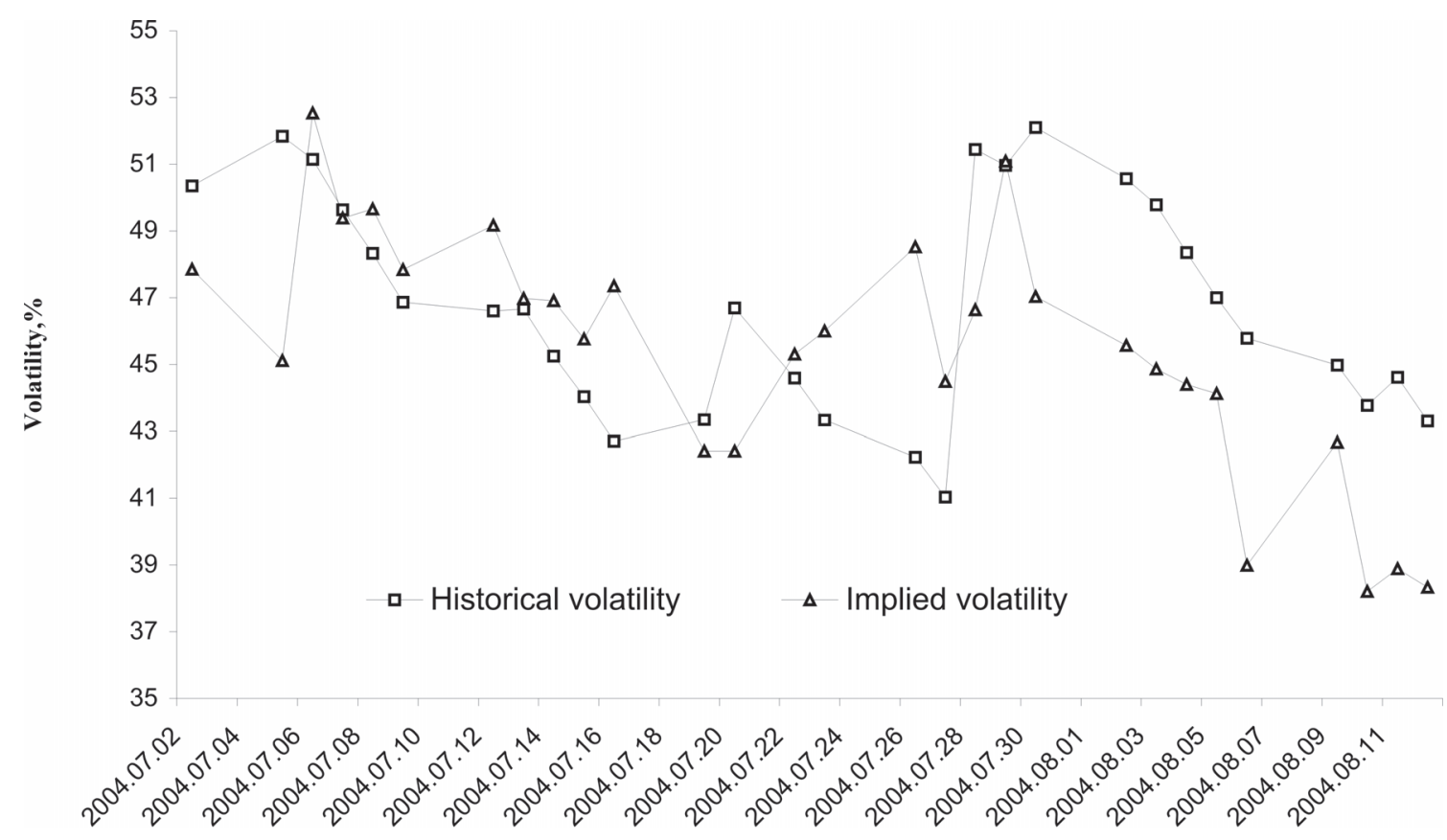

Fig 1. The example of historical and implied volatility dynamics

Black-Scholes and GARCH models of an underlying asset's price are considered. In case of GARCH application, the average hedging mistakes of BlackScholes model are negative for "at the money" options and positive for "out of the money" and "in the money" options that prove the presence of volatility smile.

The classical volatility smile is observed at the Russian option market too. The implied volatility has been estimated for the real data of the options' settlement prices. The underlying asset of the options is "EES" share's futures. The volatility smile for call options on "EES" share's futures is shown on fig. 2. The smile is constructed from options settlement prices for May, 12, 2004. The settlement price of the three-monthly future was $7564 \mathrm{RUR} /$ contract.

There are strikes of "out of the money" put options on the left tail of smile. There are strikes of "in the money" call options here too. The right tail

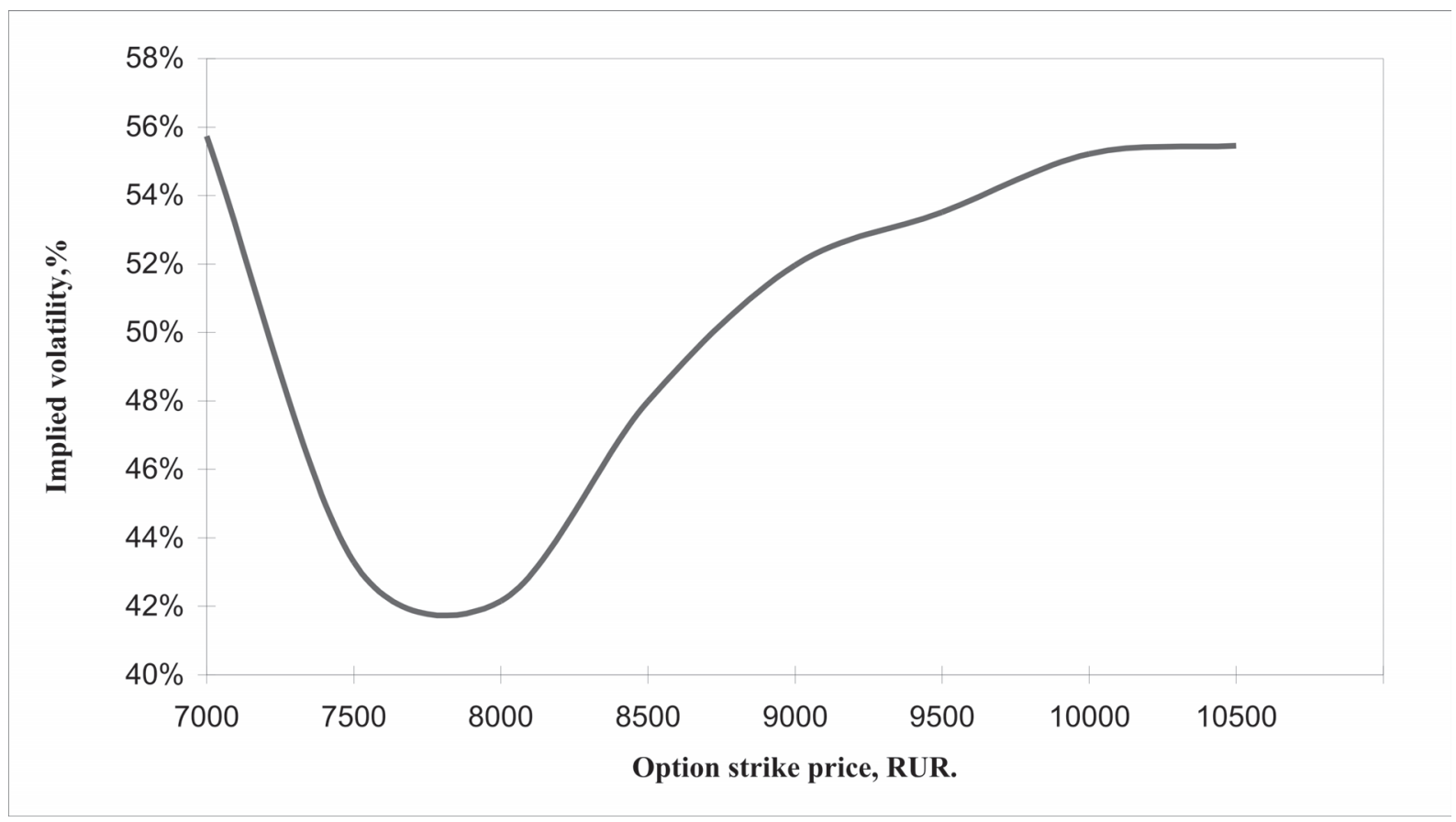

Fig 2. The volatility smile for call options on "EES" share's futures 
corresponds to strikes of "in the money" put options and "out of the money" call options. Strikes of "at the money" options are near a point of smile's minimum.

It is very interesting and important to establish, whether the presence of a volatility smile is the result of inadequacy of Black - Scholes model and whether this smile reflects a real price of option contracts.

\section{Description of the experiment}

In our research the russian shares' prices for the period from August 1999 till April 2004 are used. The shares of the following russian companies were analyzed: "Mosenergo", "EES", "Lukoil", "Rostelecom", "Sberbank" and "Surgutneftegaz". Black-Scholes model is used for the option premium calculation. The underlying assets of these options were the russian companies' shares. It is more convenient for the purposes of the research because long statistics is available. For the option premium calculation the following assumptions were used.

1. Risk free rate (as well as in works [1], [2]) was accepted equal to zero. Future and share option premiums, estimateded under Black-Scholes model, coincide at such rate.

2. Time to expiration is 20 and 60 trading days.

3 . As well as in $[2,3]$, for hedging imitation for each option expiration period was used the volatility which was estimated on the previous period with the equal duration. The volatility was calculated by a standard formula:

$$
\sigma=\sqrt{\frac{\sum\left(u_{i}-\mu\right)^{2}}{n-1}},
$$

where $\sigma$ - the historical volatility;

$u_{i}$ - the logarithm of relative increment of price in a current trading day to the price of a past trading day;

$\mu$ - the expectation of logarithmic increments;

$n$ - the sample size (20 or 60 trading days).

4. "At the money", "out of the money" and "in the money" option premiums were estimated. The option strike prices of two last categories were calculated as follows:

$$
\begin{aligned}
& X_{1}=S \times \exp ( \pm \sigma \sqrt{T}), \\
& X_{2}=S \times \exp ( \pm 2 \sigma \sqrt{T}),
\end{aligned}
$$

where $X_{1}$ - the strike price of "out of the money" and "in the money" options;

$X_{2}$ - the strike price of deeply "out of the money" and deeply "in the money" options;

$\sigma-$ a daytime volatility;

$T$ - a simulation period (20 or 60 trading days);

$S-$ a current share price in the beginning of the simulation period.

It was supposed that in the beginning of each simulation period call and put options with various strikes are sold. The quantity of the underlying asset which is necessary to sell or to purchase for each option is defined, so that the portfolios were deltaneutral. For such portfolios losses on one position are compensated by profit on another. An amount of underlying asset is defined by delta. Correction of asset's positions is carried out to ensure deltaneutrality of portfolios when market moves. Delta of call and put options are estimated by formulas (2) and (3) accordingly:

$$
\begin{aligned}
& \Delta_{\text {call }}=N\left(d_{1}\right), \\
& \Delta_{\text {put }}=N\left(d_{1}\right)-1, \\
& d_{1}=\frac{\ln \left(\frac{S}{X}\right)+\left(r+0,5 \sigma^{2}\right) T}{\sigma \sqrt{T}},
\end{aligned}
$$

where $\Delta_{\text {call }}$ - delta of call option;

$\Delta_{\text {put }}-$ delta of put option;

$N\left(d_{1}\right)$ - a function of the standard normal distribution;

$S$ - a current market price of underlying asset;

$X$ - an option strike price;

$T-$ a time to expiration of option;

$r$ - a continuously compounded free risk rate;

$\sigma-$ an underlying asset's volatility.

Delta was calculated for each trading day and according to it's value asset was purchased or sold. Delta values for "EES" shares are shown in tab. 1.

For maintenance of delta-neutrality it is necessary to buy 0,53 share on 8,957 roubles. In the second trading day it is necessary to get 0,01 more share on 9,009 roubles. In the third trading day, on the contrary, it is necessary to sell 0,03 share at the price of 8,922 roubles, etc. In the third trading day 0,03 shares had the lower price than the price of purchase. There was 
Table 1. A process of delta-hedging

\begin{tabular}{|c|c|c|c|}
\hline Trading day & Spot price, RUR. & Delta & $\begin{array}{c}\text { Results of hedging by the underlying } \\
\text { asset, RUR. }\end{array}$ \\
\hline 30.03 .2004 & 8,957 & $-0,53$ & 0,00 \\
\hline 31.03 .2004 & 9,009 & $-0,54$ & 0,03 \\
\hline 01.04 .2004 & 8,922 & $-0,51$ & $-0,05$ \\
\hline 02.04 .2004 & 8,96 & $-0,53$ & 0,02 \\
\hline
\end{tabular}

a loss as the result of this operation. The sum of profits and losses for the simulation period will form the financial result of operations with the underlying asset. It is necessary to add to this result the payments on options in case of their exercise then cumulative expenses of the option hedging will be received.

For each option expiration period and for each considered strike the hedging mistakes were estimated by means of the option premium extraction from the hedging expenses. The average mistakes of hedging for the Russian companies' shares are shown in tab. 2 and 3.
The average mistakes of hedging appeared negative for "at the money" options and positive for "in the money" and "out of the money" options. Thus, there is a volatility smile in the Russian market, and BlackScholes model do not quite adequately estimates option premiums.

Futher the coefficients of volatility smile, at which the average mistake of hedging becomes equal to zero, have been determined. A historical volatility was multiplied by the coefficients. The received new value of volatility was used for delta and option premium calculation. The coefficients of smile were calculated so that hedging

Table 2. The average mistakes of hedging for the simulation period of 20 trading days

\begin{tabular}{|c|c|c|c|c|c|c|}
\hline An option type & EES & Lukoil & Mosenergo & Rostelecom & Surgutneftegaz & Sberbank \\
\hline Put ATM & $-0,0263$ & $-0,9332$ & $-0,0066$ & $-0,1522$ & $-0,0498$ & $-14,4916$ \\
\hline Put OTM $(-\sigma)$ & 0,0114 & 0,2270 & 0,0013 & 0,0731 & 0,0135 & 3,1267 \\
\hline Put ITM $(+\sigma)$ & 0,0082 & 0,5472 & 0,0076 & 0,2540 & 0,0321 & 12,2457 \\
\hline Put OTM $(-2 \sigma)$ & 0,0024 & 0,0237 & 0,0001 & 0,0725 & 0,0009 & 0,7978 \\
\hline Put ITM $(+2 \sigma)$ & 0,0107 & 0,2641 & 0,0026 & 0,1267 & 0,0348 & 7,4121 \\
\hline Call ATM & $-0,0263$ & $-0,9332$ & $-0,0066$ & $-0,1522$ & $-0,0498$ & $-14,4916$ \\
\hline Call ITM $(-\sigma)$ & 0,0114 & 0,2270 & 0,0013 & 0,0731 & 0,0135 & 3,1267 \\
\hline Call OTM $(+\sigma)$ & 0,0082 & 0,5472 & 0,0076 & 0,2540 & 0,0321 & 12,2457 \\
\hline Call ITM $(-2 \sigma)$ & 0,0024 & 0,0237 & 0,0001 & 0,0725 & 0,0009 & 0,7978 \\
\hline Call OTM $(+2 \sigma)$ & 0,0107 & 0,2641 & 0,0026 & 0,1267 & 0,0348 & 7,4121 \\
\hline
\end{tabular}

Table 3. The average mistakes of hedging for the simulation period of 60 trading days

\begin{tabular}{|c|c|c|c|c|c|c|}
\hline An option type & EES & Lukoil & Mosenergo & Rostelecom & Surgutneftegaz & Sberbank \\
\hline Put ATM & $-0,0696$ & $-2,5884$ & $-0,0203$ & $-0,7581$ & $-0,1077$ & $-21,7309$ \\
\hline Put OTM $(-\sigma)$ & 0,0312 & 0,6892 & 0,0021 & 0,1776 & 0,0160 & 3,6844 \\
\hline Put ITM $(+\sigma)$ & 0,0125 & 1,9359 & 0,0055 & 0,3214 & 0,1001 & 6,6189 \\
\hline Put OTM $(-2 \sigma)$ & 0,0058 & 0,0592 & 0,0002 & 0,0517 & 0,0013 & 0,4139 \\
\hline Put ITM $(+2 \sigma)$ & 0,0260 & 0,1866 & 0,0056 & 0,0623 & 0,0691 & 3,7824 \\
\hline Call ATM & $-0,0696$ & $-2,5884$ & $-0,0203$ & $-0,7581$ & $-0,1077$ & $-21,7309$ \\
\hline Call ITM $(-\sigma)$ & 0,0312 & 0,6892 & 0,0021 & 0,1776 & 0,0160 & 3,6844 \\
\hline Call OTM $(+\sigma)$ & 0,0125 & 1,9359 & 0,0055 & 0,3214 & 0,1001 & 6,6189 \\
\hline Call ITM $(-2 \sigma)$ & 0,0058 & 0,0592 & 0,0002 & 0,0517 & 0,0013 & 0,4139 \\
\hline Call OTM $(+2 \sigma)$ & 0,0260 & 0,1866 & 0,0056 & 0,0623 & 0,0691 & 3,7824 \\
\hline
\end{tabular}


expenses of options by underlying assets were in the average equal to the option premiums calculated under Black-Scholes model. The iterative methods realized in MS Excel have been used for these purposes. The coefficients demonstrate a smile too.

Based on the practical reasons, the coefficients of smile have been calculated for the following russian companies: OJSC "EES" and OJSC "Lukoil". There are option trading on the companies' shares at FORTS.
With the purpose of testing of the coefficietns' stability, they were calculated for the three periods:

$>$ for all historical period;

for first half of the period from August, 1999 till June, 2002;

for second half of the period from July, 2002 till April, 2004.

The results are shown on fig 3-6.

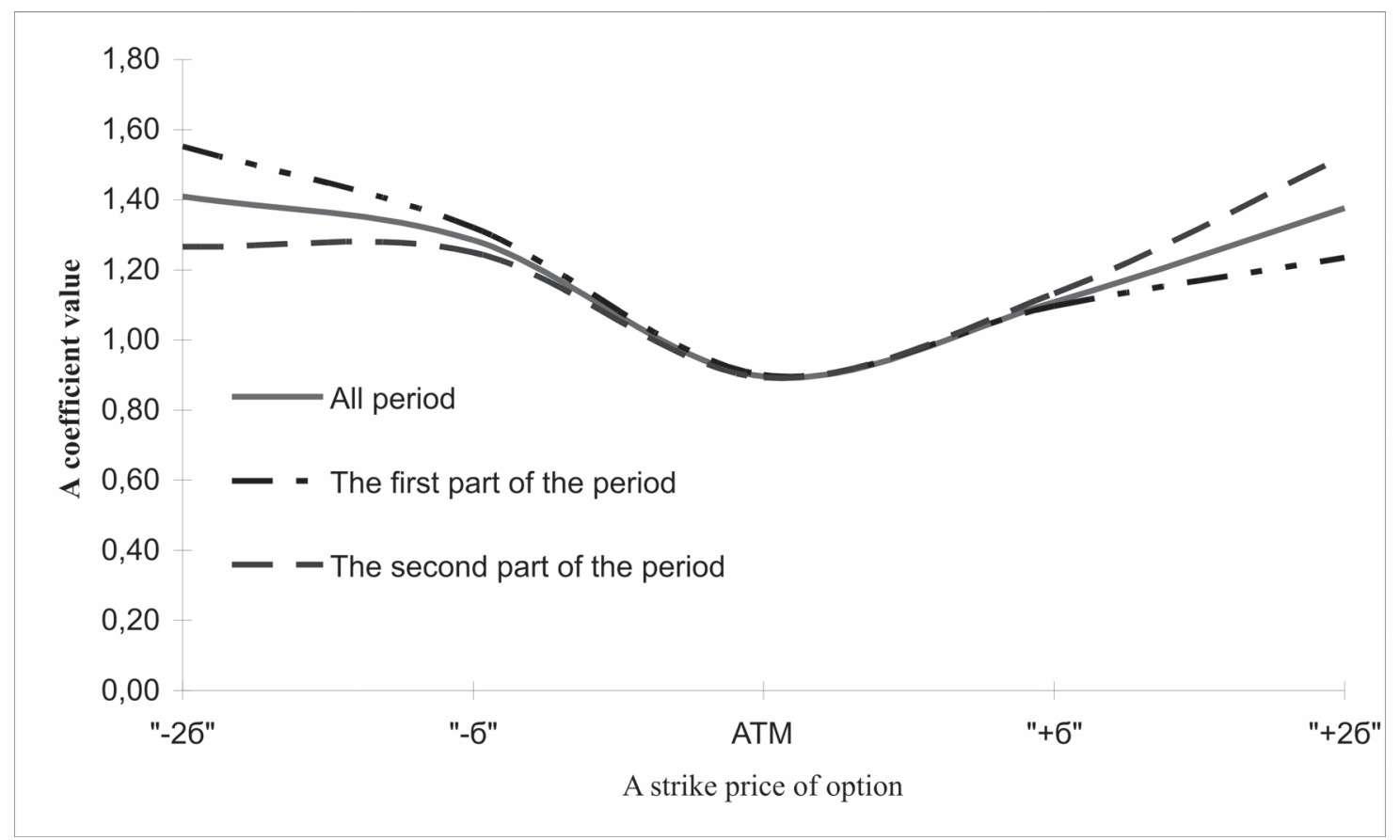

Fig 3. A volatility smile for options on "EES" shares for the simulation period of 20 trading days

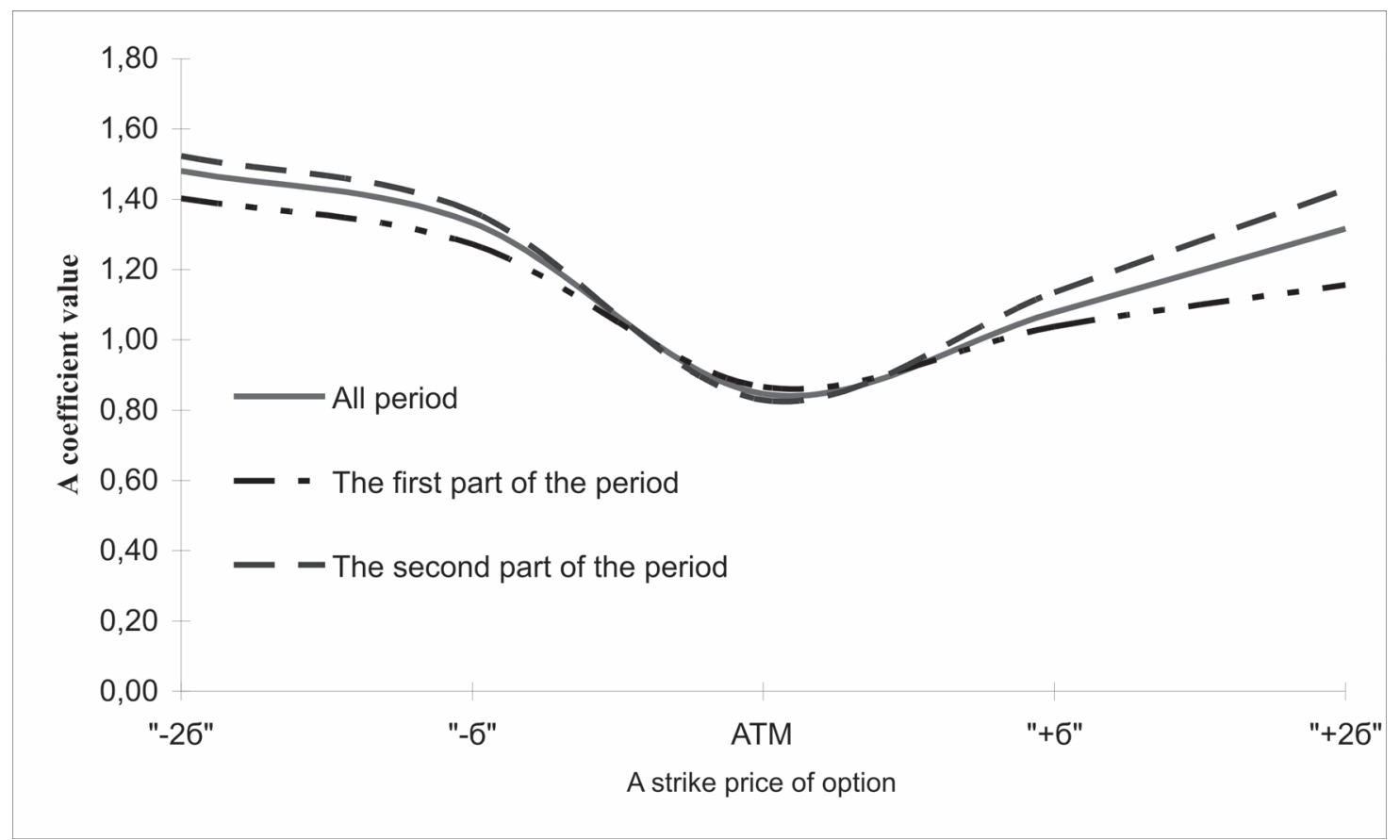

Fig 4. A volatility smile for options on "EES" shares for the simulation period of 60 trading days 


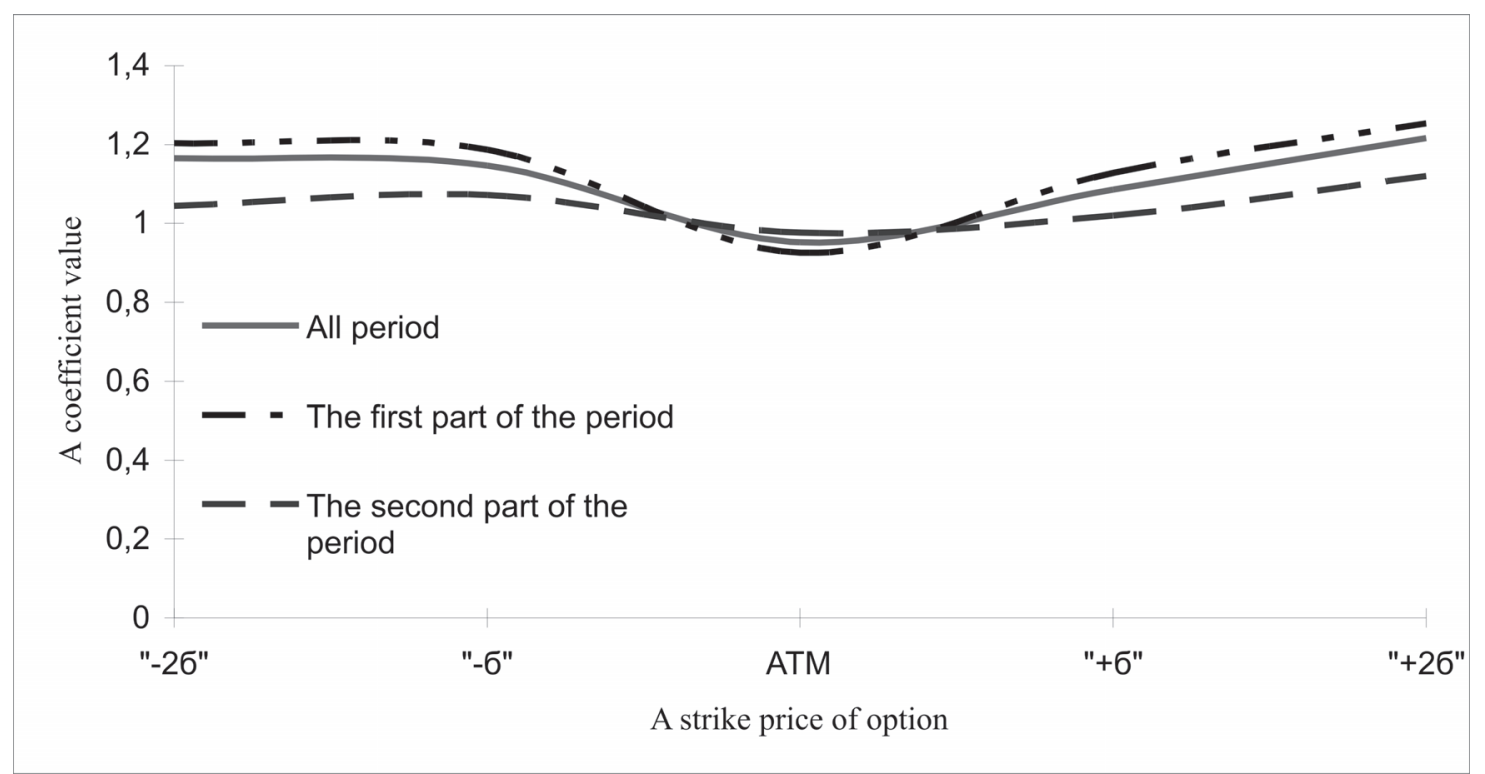

Fig 5. A volatility smile for options on "Lukoil" shares for the simulation period of 20 trading days

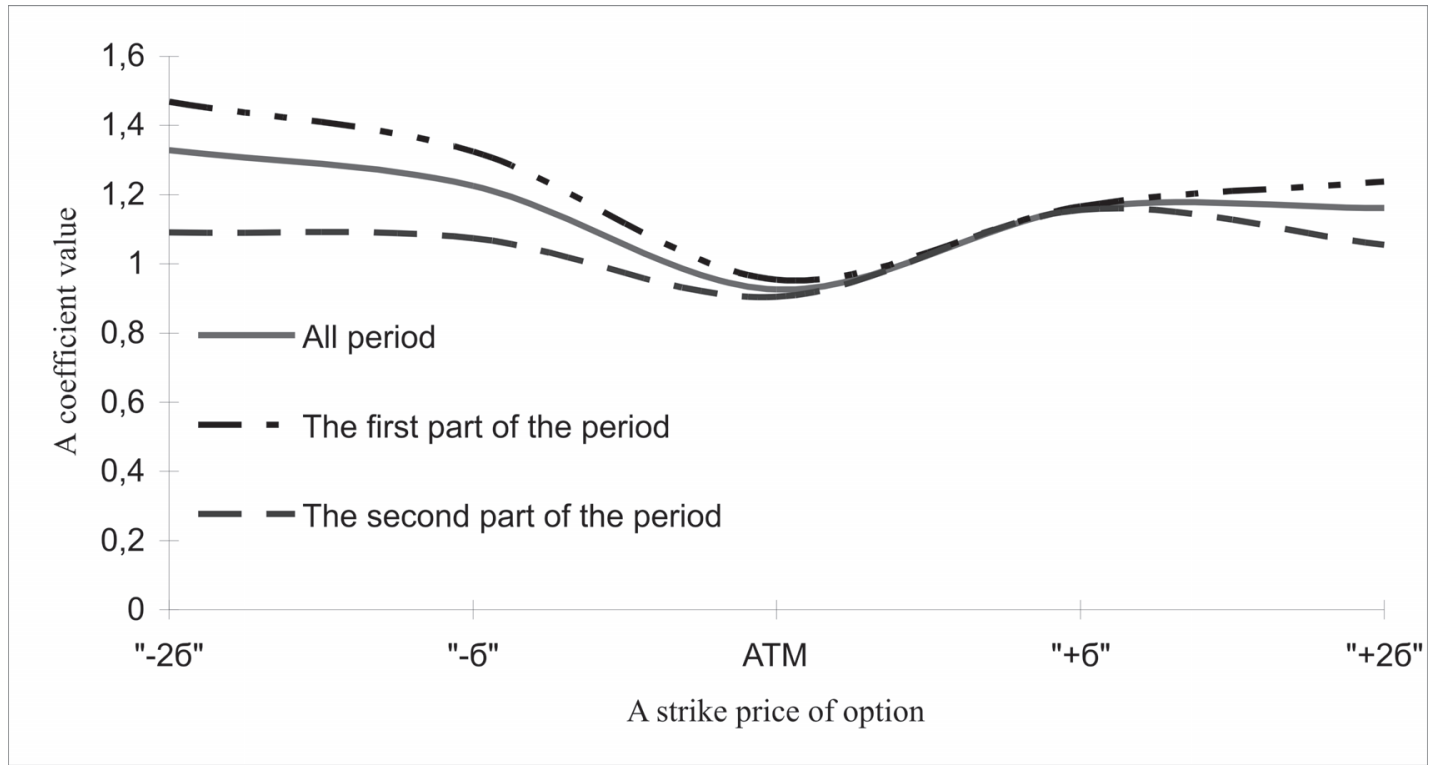

Fig 6. A volatility smile for options on "Lukoil" shares for the simulation period of 60 trading days

Fig 3-6 show that irrespectively from the historical estimation period of the coefficients a volitility smile is observed in the Russian market. A smile is quite stable and defined by the real cost of option hedging.

The received coefficients of smile have the high practical importance. They show that Black-Scholes model overestimates (if a coefficient is less than unit) or underestimates (if a coefficient is more than unit) real option premiums.

\section{Conclusions}

A classical volatility smile is observed in the Russian option market. On the average, the prices of "out of the money" and "in the money" options, calculated under Black-Scholes model, is less than their real prices. On the other hand, on the average, the value of "at the money" option premiums, calculated under Black-Scholes model, is more than the real cost of hedging by an underlying asset.

The inaccuracy of Black-Scholes model can be eliminated by calculation of coefficients of volatility smile. It is necessary to estimate a historical volatility and multiply it by a coefficient of smile to calculate a fair option premium. The received volatility is substituted in Black-Scholes model for computation of a fair option price. If a market price of an option is less than its fair price such options should be bought 
and, on the contrary, if a market price of an option is more than its fair price such options should be sold.

Black-Scholes model modification by means of coefficients of smile has the high practical importance. It allows hedgers to estimate options more efficient for hedging targets. (About application of options for hedging commodity price risks see, for example [4]).

Speculators are able to receive additional profit during the periods when market quotations of option contracts differ from their fair prices.

\section{References}

[1] Selezneva, T. V.; Tutubalin, V. N.; Uger, E. G. Imitation of practical application of the some hedging and speculative strategies. The Review of Applied and Industrial Mathematics, 1997, No 1.

[2] Geyer, A. L. J.; Schwaiger, W. S. A. Delta Hedging bei stochastischer Volatilität in diskreter Zeit (mit W.Schwaiger). Financial Markets and Portfolio Management, 15 (1), 2001, p. 94-103.

[3] Martinkute, R. Riskiness of Option Contacts and Their Combinations. Business: Theory and Practice. Vilnius: Technika, 2005, Vol 6, No 3, p. 171-179.

[4] Golembiovsky, D., Baryshnikov, I. The strategy of commodity price risk management. Questions of Economy, Moscow, 2003, No 8. 